\title{
Eosinophils Altered Phenotypically and Primed by Culture with Granulocyte/Macrophage Colony-stimulating Factor and 3T3 Fibroblasts Generate Leukotriene $\mathrm{C}_{\mathbf{4}}$ in Response to FMLP
}

William F. Owen, Jr., Jeannine Petersen, and K. Frank Austen

Department of Medicine, Harvard Medical School, and Department of Rheumatology and Immunology, Brigham and Women's Hospital, Boston, Massachusetts 02115

\begin{abstract}
Normodense eosinophils failed to generate leukotriene $\mathbf{C}_{4}$ $\left(\mathrm{LTC}_{4}\right)$ in response to incremental concentrations of FMLP but did produce $\mathrm{LTC}_{4}$ when stimulated with calcium ionophore A23187. Normodense eosinophils, maintained in culture with $10^{-11} \mathrm{M}$ granulocyte/macrophage colony-stimulating factor (GM-CSF) in the presence of $3 \mathrm{~T} 3$ fibroblasts, became responsive to transmembrane stimulation with FMLP by day 4 with a maximal effect by day 7 . After $7 \mathrm{~d}$ of culture, hypodense eosinophils stimulated with $2 \times 10^{-7}$ M FMLP generated 26 ng $\mathrm{LTC}_{4} / 10^{6}$ cells, and $\mathrm{LTC}_{4}$ biosynthesis was blocked by $\mathrm{N}$-tertbutoxy-carbonyl-L-methionyl-L-leucyl-L-phenylalanine ( $N$ - $t$ BOC-MLP). Neither calcium ionophore stimulation of LTC $_{4}$ from endogenous arachidonic acid nor substrate-initiated production of $\mathrm{LTC}_{4}$ from incorporated $\mathrm{LTA}_{4}$ changed when eosinophils were cocultured with GM-CSF and $3 T 3$ fibroblasts. Furthermore, when incubated with $10^{-6} \mathrm{M}$ FMLP, normodense eosinophils generated no net superoxide measured by the reduction of cytochrome $c$, whereas replicate esinophils cultured for $7 \mathrm{~d}$ with $10^{-11} \mathrm{M}$ GM-CSF and $3 T 3$ fibroblasts reduced a net of $17 \mathrm{nmol}$ of cytochrome $c / 10^{6}$ cells. These studies suggest that primed and phenotypically altered eosinophils present at an extravascular site may exert pathobiologic effects by responding to soluble ligands in the tissues. (J. Clin. Invest. 1991. 87:1958-1963.) Key words: granulocyte $\bullet$ cytokine $\bullet$ connective tissue $\bullet$ superoxide $\bullet$ PAF
\end{abstract}

\section{Introduction}

After stimulation with the calcium ionophore A23187 or after incorporation of the terminal substrate leukotriene (LT) ${ }^{1} \mathrm{~A}_{4}$, peripheral blood eosinophils selectively generate $\mathrm{LTC}_{4}$ and are the only human leukocytes to do so (1-4). Freshly isolated eosinophils from patients with hypereosinophilic states have a relatively lesser sedimentation density (hypodense) than eosinophils from healthy donors (normodense), and these phenoty-

Address reprint requests to Dr. Owen, The Seeley G. Mudd Building, Room 610, 250 Longwood Ave., Boston, MA 02115.

Received for publication 9 April 1990 and in revised form 29 January 1991

1. Abbreviations used in this paper: ECF-A, eosinophil chemotactic factor of anaphylaxis; GM-CSF, granulocyte/macrophage colonystimulating factor; LT, leukotriene; $N$ - $t$-BOC-MLP, $N$-tert-butoxy-carbonyl-L-methionyl-L-leucyl-L-phenylalanine; PAF, platelet activating factor.

J. Clin. Invest.

(c) The American Society for Clinical Investigation, Inc.

0021-9738/91/06/1958/06 \$2.00

Volume 87, June 1991, 1958-1963 pically altered eosinophils are primed for enhanced antibodydependent cytotoxicity against Schistosoma mansoni larvae, superoxide generation in response to FMLP, and increased $\mathrm{LTC}_{4}$ generation in response to calcium ionophore $\mathrm{A} 23187$ or immunoglobulin-coated sepharose beads (5-10). Normodense eosinophils are converted to the hypodense phenotype in vitro by coculture over a period of 4-7 d, with picomolar concentrations of granulocyte/macrophage colony-stimulating factor (GM-CSF), IL-3, or IL-5 in the presence of mouse 3T3 fibroblasts (11-13). This in vitro cytokine-dependent coculture system provides primed eosinophils that exhibit augmented antibody-dependent cytotoxicity, generate increased amounts of $\mathrm{LTC}_{4}$ when stimulated by calcium ionophore, and express CD4 and MHC epitopes on their membrane (11-15). Because freshly isolated eosinophils generate only small quantities of $\mathrm{LTC}_{4}$ in response to soluble ligands, even in the presence of cytochalasin $B(3,16)$, we studied the generation of $\mathrm{LTC}_{4}$ in response to FMLP in eosinophils that were converted to the hypodense phenotype by culture with GM-CSF in the presence of 3T3 fibroblasts. In these eosinophils, the 5-lipoxygenase pathway exhibited a substantial response to FMLP after $\sim 4 \mathrm{~d}$, and this response increased to day 7. This is the first example of any cell system in which activation of the 5-lipoxygenase pathway with a soluble stimulus has been comparable to that obtained with calcium ionophore.

\section{Methods}

Isolation and culture of human eosinophils. Human eosinophils were isolated from the peripheral blood of 13 donors who were healthy or were diagnosed as having allergic rhinitis, conjunctivitis, and/or asthma. In brief, individual dextran (BDH Chemicals, Poole, UK) sedimented erythrocyte/leukocyte preparations were centrifuged through discontinuous cushions of metrizamide (Nyegaard and Co., Oslo, Norway) of $18-24 \%$ (wt/vol) (11). Eosinophils from the 22/23 and 23/24 metrizamide interfaces and the cell pellet (normodense eosinophils) were recovered. Initial cell viability in all experiments was $>98 \%$ as assessed by the exclusion of trypan blue dye (Gibco Laboratories, Grand Island, NY)

Freshly isolated eosinophils $\left(1-2 \times 10^{6}\right.$ cells) were suspended in 2 $\mathrm{ml}$ of enriched medium (RPMI 1640 supplemented with $100 \mathrm{U} / \mathrm{ml}$ of penicillin $\mathrm{G}, 100 \mu \mathrm{g} / \mathrm{ml}$ of streptomycin, $10 \mu \mathrm{g} / \mathrm{ml}$ of gentamicin, 2 $\mathrm{mM}$ L-glutamine, $0.1 \mathrm{mM}$ nonessential amino acids, and $10 \%$ fetal bovine serum [Sigma Chemical Co., St. Louis, MO]) supplemented with $10^{-10}-10^{-12}$ M GM-CSF (Genetics Institute, Cambridge, MA), and the cells were maintained in $35-\mathrm{mm}$ plastic culture dishes in the presence or absence of a confluent monolayer of mouse 3T3 fibroblasts (line CCL 92, American Tissue Culture Collection, Rockville, MD) at $37^{\circ} \mathrm{C}$ in a $5 \% \mathrm{CO}_{2}$ atmosphere (11). The culture medium was changed every $48 \mathrm{~h}$, and fresh GM-CSF was added to the cultures. Neutrophils, which were the primary cellular contaminant, did not survive in culture for longer than $48 \mathrm{~h}$. At the desired time, the eosinophils were washed from the dishes, and their survival was determined by compar- 
ing the number of viable cells recovered with the number seeded. The cells were counted in a Neubauer counting chamber, and their viability was determined by the exclusion of trypan blue dye (11). For any time point, all functional data were based upon the number of viable eosinophils, and the data were expressed per $10^{6}$ viable cells.

Stimulation of LTC 4 production by eosinophils and assay. Freshly isolated eosinophils and their cultured replicates were washed into $3 \mathrm{ml}$ of modified Tyrode's buffer, pH 7.5, containing $0.3 \mathrm{mM} \mathrm{KCl}, 1 \mathrm{mM}$ $\mathrm{CaCl}_{2}, 5 \mathrm{mM} \mathrm{MgCl}, 0.1 \%$ (wt/vol) gelatin, and $20 \mathrm{mM}$ L-serine. L-Serine was added to minimize the hypochlorous acid-dependent oxidative metabolism of any newly formed and released sulfidopeptide leukotrienes (3). After two successive washes with modified Tyrode's buffer at $100 \mathrm{~g}$ for $10 \mathrm{~min}$ at $4^{\circ} \mathrm{C}$, the eosinophils were resuspended in the same buffer at a density of $0.4-2.0 \times 10^{6} \mathrm{cells} / \mathrm{ml}$. Samples $(500 \mu \mathrm{l})$ of the cell suspension were prewarmed for $10 \mathrm{~min}$ at $37^{\circ} \mathrm{C}$ in a humidified atmosphere of $5 \% \mathrm{CO}_{2}$. Duplicate or triplicate tubes of cells were stimulated with FMLP by the addition of $500 \mu$ l of prewarmed Tyrode's buffer containing twice the desired final concentration of FMLP. FMLP (Sigma Chemical Co.) was stored as a stock in DMSO, and the final concentration of DMSO in experiments with FMLP was $<0.1 \%$. For some experiments with FMLP, the eosinophils were preincubated for $15 \mathrm{~min}$ at $37^{\circ} \mathrm{C}$ with $N$-tert-butoxy-carbonyl-L-methionyl-L-leucylL-phenylalanine ( $N$ - $t$-BOC-MLP). As a positive control, cells were stimulated with calcium ionophore A23187 by the addition of $500 \mu$ l of

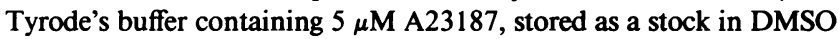
(3). For some experiments, eosinophils were stimulated with an equal volume of Tyrode's buffer containing incremental concentrations of alanyl-glycyl-seryl-glutamate (Sigma Chemical Co.) (17) or platelet-activating factor (PAF) (Calbiochem, La Jolla, CA) (18). At the desired time, the activation of the eosinophils by the agonist was terminated by the addition of $2 \mathrm{ml}$ of chilled methanol. The methanolic suspension of the entire reaction mixture was stored overnight under argon at $4^{\circ} \mathrm{C}$ to separate the supernatant from the cell pellet. For some experiments, the incubation with FMLP was terminated by immersing the tube containing the cell suspension in an ice slurry for $15 \mathrm{~min}$ followed by centrifugation at $1,000 \mathrm{~g}$ for $10 \mathrm{~min}$ at $4^{\circ} \mathrm{C}$. The individual cell pellets, containing intracellular $\mathrm{LTC}_{4}$, and the supernatants, containing released $\mathrm{LTC}_{4}$, were individually extracted overnight with methanol and processed (3).

Immunoreactive $\mathrm{LTC}_{4}$ was quantitated by RIA of the methanolic extracts $(3,11)$. In brief, the methanolic extracts were evaporated to dryness under negative pressure and resuspended in Tris-Isogel buffer. Duplicate samples were incubated for $60 \mathrm{~min}$ at $37^{\circ} \mathrm{C}$ with ${ }^{3} \mathrm{H}$-labeled $\mathrm{LTC}_{4}(40 \mathrm{Ci} / \mathrm{mmol}$, New England Nuclear, Boston, MA) and immune rabbit plasma $\left(\mathrm{ID}_{50}\right.$ values of $0.2 \mathrm{ng}$ for $\mathrm{LTC}_{4}, 0.4 \mathrm{ng}$ for $\mathrm{LTD}_{4}$, and $0.58 \mathrm{ng}$ for $\mathrm{LTE}_{4}$ ). Unbound $\mathrm{LTC}_{4}$ was removed by incubating the suspensions for $15 \mathrm{~min}$ at $4^{\circ} \mathrm{C}$ with charcoal/dextran T-40 (Sigma Chemical Co.). Synthetic $\mathrm{LTC}_{4}$ was detectable on the linear portion of the radioligand inhibition-binding curve at concentrations ranging from 0.4 to $4.0 \mathrm{ng} / \mathrm{ml}$. The identity of immunoreactive $\mathrm{LTC}_{4}$ was confirmed by reverse-phase HPLC of the methanolic extract of FMLPstimulated cells. PGB (100 ng) (Cayman Chemical Co., Ann Arbor, MI) was added as an internal standard. Each sample was applied to a $5-\mu \mathrm{m}, 4.6 \times 250-\mathrm{mm} \mathrm{C}_{18}$ Ultrasphere reverse phase column (Beckman Instruments, Inc., Wakefield, MA) and eluted at a flow rate of $1 \mathrm{ml} /$ min with a solvent of methanol/water/acetic acid (65:34.9:0.1, vol/ vol), $\mathrm{pH} 5.6$, containing $0.02 \%$ disodium EDTA (4). On-line ultraviolet absorbance was monitored at $280 \mathrm{~nm}$ for $\mathrm{LTC}_{4}$ (retention time, 10.0 \pm 0.1 min; mean \pm SEM, $n=14$ ).

Assay of cellular LTC 4 synthase activity. LTA methyl ester was synthesized and provided by Drs. E. J. Corey and B. Spur (Harvard University) (19), and was hydrolyzed as described (20). Freshly isolated, cultured eosinophils were washed twice with PBS, pH 7.4, containing $2 \mathrm{mg} / \mathrm{ml} \mathrm{BSA}$, and resuspended in the same buffer at $2-5 \times 10^{6}$ cells $/ \mathrm{ml}$. Then, $1-\mathrm{ml}$ portions of this suspension were prewarmed to $37^{\circ} \mathrm{C}$ for $5 \mathrm{~min}$, mixed with $2.5 \times 10^{-5} \mathrm{M} \mathrm{LTA}_{4}$ (dissolved in $1 \mu \mathrm{l}$ of methanol), and incubated for $15 \mathrm{~min}$ at $37^{\circ} \mathrm{C}(4)$. The incubation was terminated by immersing the tube containing the cell suspension in an ice slurry for $15 \mathrm{~min}$, followed by centrifugation at $1,000 \mathrm{~g}$ for $10 \mathrm{~min}$ at $4^{\circ} \mathrm{C}$. The cell pellet and supernatant were extracted overnight with methanol, and $\mathrm{LTC}_{4}$ was quantitated by integrative optical density.

Stimulation and assay of superoxide production by eosinophils. Freshly isolated eosinophils and their cultured replicates were washed into HBSS with calcium and magnesium supplemented with $5 \%$ FBS, 1 mM Hepes, and $0.1 \%$ BSA, and were resuspended at a density of 6.25$12.5 \times 10^{5} \mathrm{cells} / \mathrm{ml}$. Samples $(800 \mu \mathrm{l})$ of the cell suspension were combined with $100 \mu$ l of freshly prepared cytochrome $c$ (Sigma Chemical Co.; type $\mathrm{V}, 10 \mathrm{mg} / \mathrm{ml}$ ) in HBSS without calcium and magnesium (HBSS $^{-}$) with or without the addition of $20 \mu$ of superoxide dismutase (Sigma Chemical Co.; $1 \mathrm{mg} / \mathrm{ml}$ ), and the tubes were placed in a shaking water bath at $37^{\circ} \mathrm{C}$ for $10 \mathrm{~min}$. Various concentrations of FMLP were added to produce a final volume of $1 \mathrm{ml}$, and incubations were continued for an additional $15 \mathrm{~min}(21)$. The reactions were terminated by rapidly cooling the samples and centrifuging them at $1,000 \mathrm{~g}$ for $15 \mathrm{~min}$ at $4^{\circ} \mathrm{C}$. The supernatants were immediately transferred to individual wells of a 96-well microtiter plate for measurement of reduced cytochrome $c$ at an absorbance of $550 \mathrm{~nm}$ using an extinction coefficient of $18.5 \mathrm{mM}^{-1}$.

Statistical analysis. The statistical significance of differences between sample means for each set of eosinophils was based upon comparisons as determined by the two-tailed Student's $t$ test.

\section{Results}

LTC 4 production by FMLP-stimulated eosinophils. Freshly isolated eosinophils, incubated for 10 or $60 \mathrm{~min}$ at $37^{\circ} \mathrm{C}$ with incremental concentrations of FMLP up to $2 \times 10^{-5} \mathrm{M}$ generated $<1 \mathrm{ng}$ of $\mathrm{LTC}_{4} / 10^{6}$ cells $(n=3)$. Replicate suspensions of eosinophils stimulated for 10 min with $2.5 \times 10^{-6} \mathrm{M}$ calcium ionophore $\mathrm{A} 23187$ generated $60 \pm 18 \mathrm{ng}$ of $\mathrm{LTC}_{4} / 10^{6}$ cells (mean \pm SEM, $n=3$ ). Replicate eosinophils cultured for $7 \mathrm{~d}$ with $10^{-10}, 10^{-11}$, and $10^{-12} \mathrm{M} \mathrm{GM-CSF}$ in the presence of 3T3 fibroblasts and washed before the addition of $2 \times 10^{-6} \mathrm{M}$ FMLP generated $13 \pm 2,24 \pm 5$, and $23 \pm 5 \mathrm{ng}$ of $\mathrm{LTC}_{4} / 10^{6}$ cells (mean $\pm \operatorname{SEM}, n=3$ ), respectively. Eosinophil survival to $7 \mathrm{~d}$ in culture did not occur using GM-CSF concentrations $<10^{-12} \mathrm{M}$ (data not shown). Because $10^{-11} \mathrm{M}$ GM-CSF was the concentration which resulted in optimal eosinophil survival ex vivo to 7-14 d (12), and no significant improvement in FMLP-stimulated $\mathrm{LTC}_{4}$ generation occurred using higher concentrations of this cytokine, all subsequent experiments were performed using eosinophils maintained in culture with $10^{-11} \mathrm{M}$ GM-CSF.

Eosinophils cultured for $7 \mathrm{~d}$ with $10^{-11} \mathrm{M}$ GM-CSF in the presence of 3T3 fibroblasts and washed before the addition of agonist generated $\mathrm{LTC}_{4}$ in a dose-dependent fashion in response to FMLP (Fig. 1). The observed $\mathrm{ED}_{50}$ for $\mathrm{LTC}_{4}$ generation was $\sim 2 \times 10^{-8} \mathrm{M}$ FMLP, and maximum LTC $_{4}$ generation occurred at concentrations of $2 \times 10^{-7} \mathrm{M}$ FMLP or greater. This dose-response to FMLP was not changed by increasing the duration of incubation with the agonist to $60 \mathrm{~min}$ (data not shown). In order to be on the plateau of the dose-response curve, a concentration of $2 \times 10^{-6} \mathrm{M}$ FMLP was selected as the routine dose. When stimulated for $10 \mathrm{~min}$ at $37^{\circ} \mathrm{C}$ with $2 \times 10^{-6} \mathrm{M}$ FMLP, the replicate cultured eosinophils generated $42 \pm 6 \mathrm{ng}$ of $\mathrm{LTC}_{4} / 10^{6}$ cells $(n=3)$, which was $\sim 70 \%$ the amount generated by replicate eosinophils stimulated with calcium ionophore A23187.

To confirm the identity of the immunoreactive $\mathrm{LTC}_{4}, 6$ $\times 10^{6}$ eosinophils that had been cultured for $7 \mathrm{~d}$ with GM-CSF in the presence of $3 \mathrm{~T} 3$ fibroblasts were stimulated for $10 \mathrm{~min}$ with $2 \times 10^{-6} \mathrm{M}$ FMLP, and a portion of the methanolic ex- 


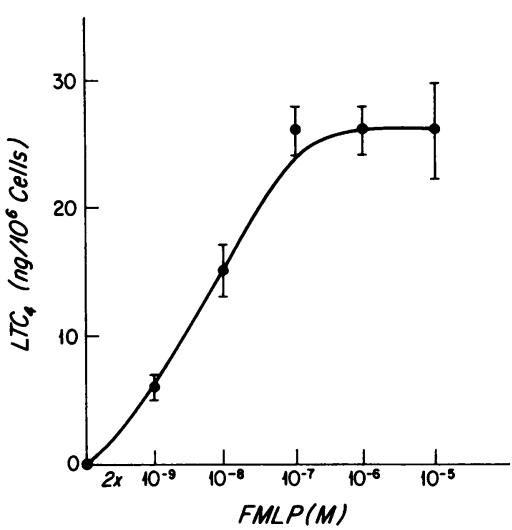

Figure 1. Dose-dependent FMLP-initiated $\mathrm{LTC}_{4}$ production by eosinophils cultured for 7 $d$ in $10^{-11} \mathrm{M} \mathrm{GM}-\mathrm{CSF}$ in the presence of $3 \mathrm{~T} 3$ fibroblasts. The eosinophils were stimulated for $10 \mathrm{~min}$, the total reaction mixture was extracted with methanol, and $\mathrm{LTC}_{4}$ was measured by RIA. Data are expressed as the mean \pm SEM for three experiments.

tract of the reaction mixture was analyzed for the quantity of sulfidopeptide leukotrienes by RP-HPLC. An ultraviolet absorbing peak was detected at the retention time of synthetic $\mathrm{LTC}_{4}$; no other peaks were detected (data not shown). 1-ml fractions of the eluant were collected, evaporated to dryness under negative pressure, resuspended in aqueous buffer, and subjected to RIA. A small quantity of immunoreactive material eluted at the retention time of $\mathrm{LTD}_{4}$ and no immunoreactivity was detected at the retention time of $\mathrm{LTE}_{4}$. By integrated optical density and by RIA, the amounts of $\mathrm{LTC}_{4}$ present were 58 and $42 \mathrm{ng}$, respectively.

$\mathrm{LTC}_{4}$ was generated by eosinophils cultured for $7 \mathrm{~d}$ with GM-CSF and 3T3 fibroblasts in a time-dependent manner; near maximum biosynthesis was observed $5 \mathrm{~min}$ after the addition of FMLP (Fig. 2). In an experiment, at 1, 5, 10, and $15 \mathrm{~min}$ after the addition of FMLP to the cell suspension 100, 61, 39, and $30 \%$, respectively, of the total amount of $\mathrm{LTC}_{4}$ generated remained intracellular, and $50,43,43$, and $28 \%$, respectively, was intracellular in another experiment.

Kinetics of the GM-CSF-mediated acquisition of the eosinophil response to FMLP. Freshly isolated eosinophils were cultured for 1-336 h with $10^{-11} \mathrm{M}$ GM-CSF and 3T3 fibroblasts,

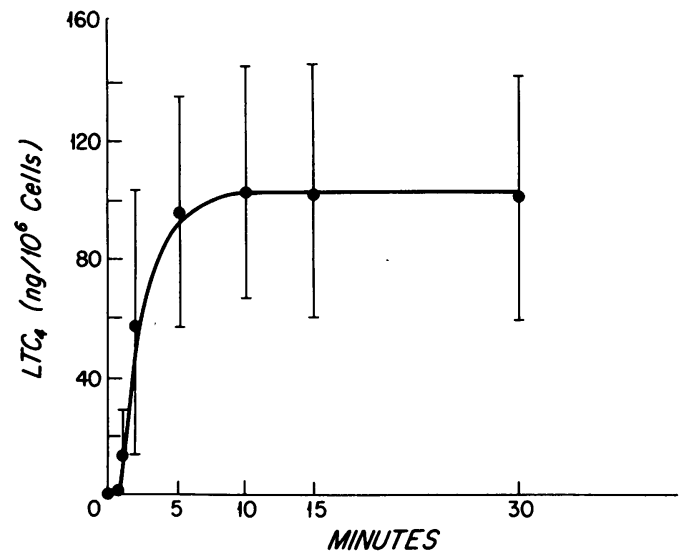

Figure 2. Time course of $\mathrm{LTC}_{4}$ generation by eosinophils cultured for $7 \mathrm{~d}$ in GM-CSF in the presence of 3T3 fibroblasts. The eosinophils were stimulated with $2 \times 10^{-6} \mathrm{M}$ FMLP, and the total reaction mixture was extracted with methanol. Data are expressed as the mean \pm SEM for five experiments, except for the data points at 1 and $2 \mathrm{~min}$, which are the mean of four experiments. then washed and stimulated for 10 min with $2 \times 10^{-6} \mathrm{M} \mathrm{FMLP}$ or $2.5 \times 10^{-6} \mathrm{M}$ calcium ionophore $\mathrm{A}^{23187}$. $\mathrm{LTC}_{4}$ generation by the eosinophils in response to FMLP was acquired over several days, accelerated after day 4, and did not approach a plateau until $\sim 14 \mathrm{~d}$ of culture (Fig. $3 A$ ). For calcium ionophore-stimulated cells, an $\sim 2.5$-fold augmentation in $\mathrm{LTC}_{4}$ generation was noted after a 60 -min exposure to GM-CSF, and remained significantly increased over the subsequent $7 \mathrm{~d}$ of culture (Fig. $3 B)\left(P<0.05\right.$ for $\mathrm{LTC}_{4}$ generation by eosinophils exposed to GM-CSF as compared with that by freshly isolated cells). For some experiments, replicate freshly isolated eosinophils were cultured for $7 \mathrm{~d}$ in $10^{-11} \mathrm{M} \mathrm{GM}$-CSF in the presence or absence of a monolayer of 3T3 fibroblasts. The cells were washed, and equal numbers of viable cells were stimulated for 10 min with $2 \times 10^{-6} \mathrm{FMLP}$. Eosinophils cultured in the presence of a fibroblast monolayer generated $51 \pm 8 \mathrm{ng}$ of $\mathrm{LTC}_{4} / 10^{6}$ cells, whereas replicate eosinophils cultured in the absence of a monolayer generated only $12 \pm 4 \mathrm{ng}$ of $\mathrm{LTC}_{4} / 10^{6}$ cells (mean \pm SEM, $n=3)(P<0.05)$.

Characterization of the ligand specificity for $L_{T} C_{4}$ generation. Competition studies were performed with FMLP and its structural antagonist, $N$ - $t$-BOC-MLP $(3,22)$. After culture for 7 $\mathrm{d}$, eosinophils were washed, resuspended in buffer containing $N$ - $t$-BOC-MLP, and incubated for $15 \mathrm{~min}$ at $37^{\circ} \mathrm{C}$. FMLP was added, and the incubation was continued for $10 \mathrm{~min}$ more. Replicate eosinophils were preincubated with buffer alone and stimulated in parallel with FMLP. Eosinophils preincubated in
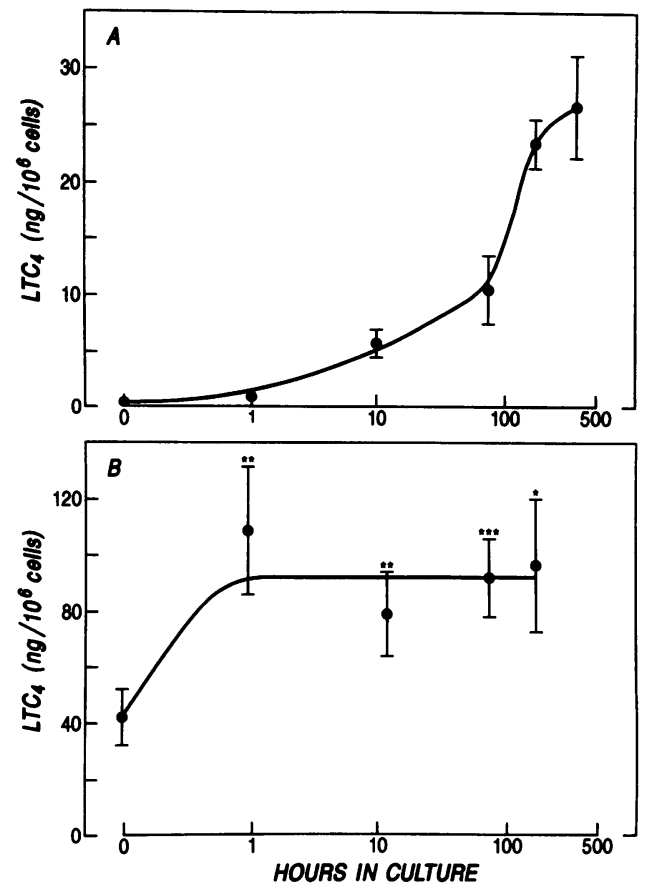

Figure 3. Time course of the change in FMLP-stimulated LTC production by eosinophils maintained in coculture with GM-CSF and $3 \mathrm{~T} 3$ fibroblasts. After the designated culture intervals, replicate eosinophils were stimulated for 10 min with $2 \times 10^{-6} \mathrm{M}$ FMLP $(A)$ or $2.5 \times 10^{-6} \mathrm{M}$ calcium ionophore $\mathrm{A} 23187(B)$, and the total reaction mixture was extracted with methanol and assayed for LTC $_{4}$ by RIA. Data are expressed as the mean \pm SEM for four experiments in $A$ and five experiments in $B$. Statistically significant increases in A23187-stimulated $\mathrm{LTC}_{4}$ generation as compared to that of freshly isolated replicate eosinophils $\left({ }^{*} P<0.05 ;{ }^{* *} P<0.02\right.$; $\left.{ }^{* * *} P<0.01\right)$. 
buffer and stimulated with $2 \times 10^{-6}$ and $0.2 \times 10^{-6} \mathrm{M}$ FMLP generated $55 \pm 7$ and $45 \pm 11 \mathrm{ng}$ of $\mathrm{LTC}_{4} / 10^{6}$ cells $(n=3$, mean \pm SEM), respectively, whereas eosinophils preincubated with $2 \times 10^{-5} \mathrm{M} \mathrm{N}-t$-BOC-MLP and stimulated with the same concentrations of FMLP generated the reduced amounts of $33 \pm 7$ and $16 \pm 11 \mathrm{ng}$ of $\mathrm{LTC}_{4} / 10^{6}$ cells, respectively. When the $N$ - $t$-BOC-MLP concentration was decreased 10 -fold to 2 $\times 10^{-6} \mathrm{M}$, FMLP-stimulated $\mathrm{LTC}_{4}$ generation increased to $45 \pm 6$ and $36 \pm 9 \mathrm{ng} / 10^{6}$ cells, respectively. Thus, equimolar concentrations of FMLP and $N$ - $t$-BOC-MLP $\left(2 \times 10^{-6} \mathrm{M}\right)$ permitted $\mathrm{LTC}_{4}$ to be generated in an amount equal to that obtained with a one log lesser dose of FMLP alone.

Eosinophils were cultured for $7 \mathrm{~d}$ with GM-CSF in the presence of 3T3 fibroblasts, and replicate samples were stimulated for 10 min with $2 \times 10^{-6} \mathrm{M}$ FMLP or incremental concentrations of other eosinophil chemotactic agonists, eosinophil chemotactic factor of anaphylaxis (ECF-A) and PAF. In two experiments, no $\mathrm{LTC}_{4}$ was detected from the eosinophils stimulated with concentrations of ECF-A as great as $2 \times 10^{-5} \mathrm{M}$, whereas the FMLP-stimulated cells produced 24 and $48 \mathrm{ng}$ of $\mathrm{LTC}_{4} / 10^{6}$ cells, respectively. Even in the presence of concentrations of PAF as great as $10^{-5} \mathrm{M}$, no $\mathrm{LTC}_{4}$ was detected, whereas the FMLP-stimulated replicate eosinophils produced 14 and $42 \mathrm{ng}$ of $\mathrm{LTC}_{4} / 10^{6}$ cells, respectively.

LTC $C_{4}$ synthase activity of freshly isolated and cultured eosinophils. To determine $\mathrm{LTC}_{4}$ synthase activity, freshly isolated eosinophils and replicate cells maintained in culture with GM-CSF in the presence of 3T3 fibroblasts were incubated with $\mathrm{LTA}_{4}$ (Fig. 4). Freshly isolated eosinophils generated $206 \pm 21 \mathrm{ng}$ of $\mathrm{LTC}_{4} / 10^{6}$ cells, whereas cells maintained in culture for 7 and $14 \mathrm{~d}$ produced $180 \pm 22$ and $175 \pm 14 \mathrm{ng}$ of $\mathrm{LTC}_{4} /$ $10^{6}$ cells, respectively. LTC $_{4}$ production from endogenously generated substrate by replicate eosinophils stimulated with 2 $\times 10^{-6} \mathrm{M}$ FMLP was 0,19 , and $20 \mathrm{ng} / 10^{6}$ cells on days 0,7 , and

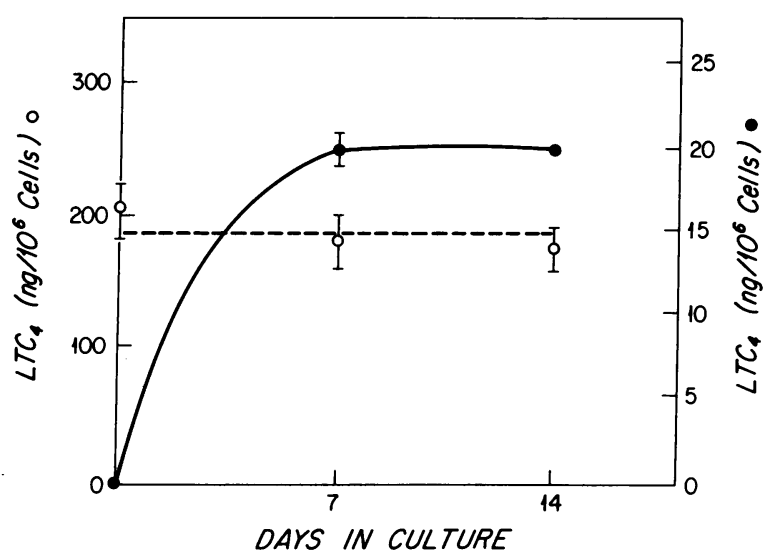

Figure 4. Influence of the duration of coculture with GM-CSF and 3 T3 fibroblasts on $\mathrm{LTC}_{4}$ synthase activity (o, left scale) and FMLP-stimulated $\mathrm{LTC}_{4}$ production (๑, right scale) by replicate eosinophils. The eosinophils were cultured for the desired intervals. To measure $\mathrm{LTC}_{4}$ synthase activity, $2.5 \times 10^{-5} \mathrm{M} \mathrm{LTA}_{4}$ was added to the cells for $15 \mathrm{~min}$, the total reaction mixture was extracted with methanol, and $\mathrm{LTC}_{4}$ generation was quantitated by integrative optical density. FMLP-stimulated $\mathrm{LTC}_{4}$ production was assayed by RIA of the total reaction mixture after the cells were incubated for $10 \mathrm{~min}$ with $2 \times 10^{-6} \mathrm{M}$ FMLP. The data are expressed as the mean \pm SEM for $\mathrm{LTC}_{4}$ synthase ( $n=4$, except for day 14 when $\left.n=3\right)$, and as the mean \pm half-range for FMLP-stimulated $\mathrm{LTC}_{4}$ production $(n=2)$.
14 of culture, respectively (Fig. 4) for one experiment, and 0 , 21 , and $20 \mathrm{ng} / 10^{6}$ cells, respectively, in another experiment. Thus, the latency noted for the membrane-transduced LTC $_{4}$ response to FMLP was not apparent for the circumstance in which exogenous substrate interacted directly with $\mathrm{LTC}_{4}$ synthase.

Superoxide generation by freshly isolated and cultured eosinophils. In five experiments in which freshly isolated eosinophils were stimulated with incremental concentrations of FMLP, only minimal net reduction of cytochrome $c$ was observed at FMLP doses of $\leq 10^{-6} \mathrm{M}$. When stimulated with $10^{-6}$ M FMLP, replicate eosinophils which had been cultured for $7 \mathrm{~d}$ with $10^{-11} \mathrm{M}$ GM-CSF in the presence of $3 \mathrm{~T} 3 \mathrm{fibroblasts}$ reduced $21 \pm 7 \mathrm{nmol}$ of cytochrome $c / 10^{6}$ cells, and the extrapolated $\mathrm{ED}_{50}$ was $\sim 10^{-8} \mathrm{M}$ FMLP (Fig. 5). In the absence of FMLP stimulation, freshly isolated eosinophils reduced $3 \pm 1$ nmol of cytochrome $c / 10^{6}$ cells, and their cultured replicates reduced $4 \pm 2 \mathrm{nmol}$ of cytochrome $c / 10^{6}$ cells. Superoxide dismutase completely abolished the spontaneous and FMLPstimulated reduction of cytochrome $c$ (data not shown).

\section{Discussion}

The hematopoietic generation of eosinophils from bone marrow progenitors depends upon the action of a group of glycoprotein cytokines that are segregated to the short arm of chromosome 5: GM-CSF, IL-3, and IL-5 $(23,24)$. These same three cytokines also alter the viability and function of mature eosinophils in vitro (11-13). This regulatory role for IL-5 has been noted in vivo in the pathologic state of the idiopathic hypereosinophilic syndrome (IHES) (25). In IHES, the cytokine-dependent priming of the eosinophils is so marked that, in comparison to the eosinophils from healthy donors, the normodense eosinophils exhibit greatly augmented antibody-dependent cytotoxicity, and the hypodense eosinophils mediate cytotoxicity in the absence of antibody directed against the target $S$. mansoni (25). In the case of eosinophils of the hypodense phenotype that are generated in vitro by culture with IL-3, GM-CSF, or IL-5, the augmentation of antibody-dependent cytotoxicity exhibited at $7 \mathrm{~d}$ is fully dependent upon the presence of 3T3 fibroblasts during culture, whereas the enhancement of calcium ionophore-stimulated $\mathrm{LTC}_{4}$ generation is mediated by the cytokine alone $(11,13)$. Because the effect of

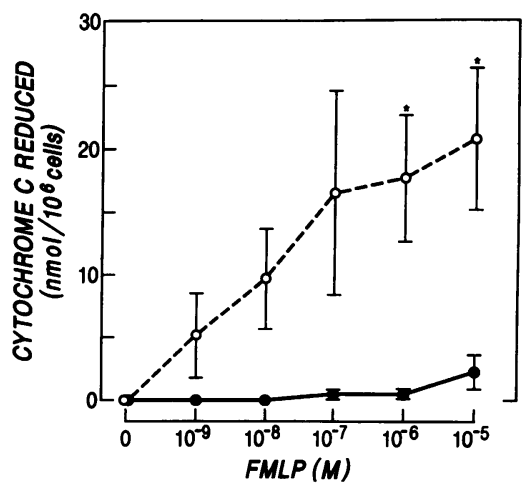

Figure 5. Effect of incremental concentrations of FMLP on net superoxide generation by freshly isolated eosinophils (•) and replicate eosinophils cultured for $7 \mathrm{~d}$ with $10^{-11}$ $M$ GM-CSF and 3T3 fibroblasts (0). Cytochrome $c$ reduction was monitored at 550 $\mathrm{nm}$ and values shown represent the

mean \pm SEM for five experiments. *Statistically significant increase in FMLP-stimulated superoxide generation as compared with that of freshly isolated replicate eosinophils $(P<0.05)$. 
cytokine priming on antibody-dependent cytotoxicity involves the transduction of a transmembrane stimulus, we examined the influence of cytokine-driven alterations in eosinophil phenotype on their capacity to generate $\mathrm{LTC}_{4}$ in response to the soluble transmembrane agonist, FMLP.

Freshly isolated normodense eosinophils did not respond to micromolar concentrations of FMLP with the production of detectable quantities of $\mathrm{LTC}_{4}$. However, as the eosinophils were maintained in culture with $10^{-10}-10^{-12} \mathrm{M}$ GM-CSF in the presence of 3T3 fibroblasts, they became increasingly more responsive to FMLP as an agonist for $\mathrm{LTC}_{4}$ generation. When maintained in coculture with $10^{-11} \mathrm{M} \mathrm{GM}-\mathrm{CSF}$ and 3T3 fibroblasts, a gradual increase in FMLP-stimulated $\mathrm{LTC}_{4}$ biosynthesis occurred over the first $4 \mathrm{~d}$ of culture, followed by an accelerated increase to day 7 (Fig. $3 \mathrm{~A}$ ). This effect of coculture is temporally associated with a progressive conversion of the eosinophils to the hypodense phenotype $(11-13,26)$. LTC $_{4}$ biosynthesis in response to FMLP occurred in a dose-dependent manner, with an observed $\mathrm{ED}_{50}$ of $\sim 2 \times 10^{-8} \mathrm{M}$ FMLP and was maximum at FMLP concentrations of $2 \times 10^{-7} \mathrm{M}$ or greater (Fig. 1). The quantity of $\mathrm{LTC}_{4}$ elaborated by $7 \mathrm{~d}$ cultured eosinophils which were stimulated for 10 min with 2 $\times 10^{-6}$ M FMLP was $69 \pm 19 \mathrm{ng} / 10^{6}$ cells $(n=6)$; replicate cultured eosinophils stimulated with calcium ionophore A23187 elaborated $111 \pm 17 \mathrm{ng} / 10^{6}$ cells $(P<0.10)$. FMLP-stimulated biosynthesis of $\mathrm{LTC}_{4}$ was rapid with initial intracellular accumulation $(3,4)$, and total $\mathrm{LTC}_{4}$ generation was completed within $5 \mathrm{~min}$ (Fig. 2). Analogous to the situation for another transmembrane-mediated response, antibody-dependent cytotoxicity $(11,13)$, optimal expression of the FMLP-stimulated $\mathrm{LTC}_{4}$ generation required that the eosinophils be cultured in the presence of a fibroblast monolayer.

For all experiments, there was a fivefold range for $\mathrm{LTC}_{4}$ production by eosinophils which were cocultured with GMCSF and 3T3 fibroblasts and stimulated with FMLP. This is comparable with previous data which revealed similar variability for $\mathrm{LTC}_{4}$ generation by A23187-stimulated freshly-isolated normodense eosinophils $(3,11)$. The biochemical basis of this variability in $\mathrm{LTC}_{4}$ generation for eosinophils stimulated with either FMLP or A23187 suggests that donor differences may exist in enzymatic activity or substrate availability for the 5-lipoxygenase pathway. The role of differential responsiveness to GM-CSF and 3T3 fibroblasts as priming factors for FMLP includes receptor number and affinity, and signal transduction may further contribute to eosinophil donor variability in $\mathrm{LTC}_{4}$ synthesis in response to FMLP.

$\mathrm{LTC}_{4}$ synthase, which adducts glutathione to $\mathrm{LTA}_{4}$, is the terminal enzyme in the biosynthesis of $\operatorname{LTC}_{4}(3,20)$, and, analogous to the xenobiotic-metabolizing glutathionyl S-transferases, it may be inducible (27). The ability of intact eosinophils to take up $\mathrm{LTA}_{4}$, and to further metabolize this substrate to $\mathrm{LTC}_{4}$ in the absence of an added agonist (4), allowed a functional estimate of the cellular $\mathrm{LTC}_{4}$ synthase activity. Over $14 \mathrm{~d}$ of culture in GM-CSF in the presence of 3T3 fibroblasts, no change occurred in $\mathrm{LTC}_{4}$ synthase activity (Fig. 4). Furthermore, after $1 \mathrm{~h}$ of coculture with GM-CSF and 3T3 fibroblasts, the calcium ionophore-stimulated generation of $\mathrm{LTC}_{4}$ was augmented for $7 \mathrm{~d}$ of observation (Fig. $3 \mathrm{~B}$ ). During the same interval in which FMLP-initiated $\mathrm{LTC}_{4}$ production was increasing progressively, the finding that coculture did not alter either the response to the substrate for $\mathrm{LTC}_{4}$ synthase, or the postmembrane response to ionophore, suggests that this cyto- kine-dependent upregulation of FMLP-stimulated $\mathrm{LTC}_{4}$ generation must occur at steps proximal to the 5-lipoxygenase.

The demonstration that the FMLP-stimulated generation of LTC $_{4}$ by eosinophils is time-dependent and cytokine-dependent suggests the occurrence of new protein synthesis relevant to signal transduction. Another study has demonstrated the biosynthesis of new proteins by hypodense eosinophils (28). In the neutrophil, a 30-min preincubation with GM-CSF augments the rise in cytosolic calcium in response to FMLP (29). Furthermore, several studies have suggested that the shortterm exposure of neutrophils to GM-CSF may directly stimulate or augment phospholipase activity in response to FMLP (30-32). Even if these effects of GM-CSF are operative in the hypodense eosinophil, activation by FMLP would still require the presence of FMLP receptors, as suggested by the blocking action of $N$ - $t$-BOC-MLP. $N$ - $t$-BOC-MLP, a stereospecific antagonist of FMLP-induced chemotaxis, as defined in a neutrophil system (22), attenuated the ability of FMLP to stimulate LTC generation. The addition of an equimolar concentration of $N$ - $t$ BOC-MLP to the assay resulted in a decrease in $\mathrm{LTC}_{4}$ generation to the level achieved with stimulation by a one log lesser concentration of FMLP alone. As compared to FMLP, the failure to demonstrate significant $\mathrm{LTC}_{4}$ generation in response to stimulation with PAF and ECF-A implies some selectivity in the up-regulation of the capacity to respond to soluble ligands in the presence of a change in phenotype (16).

In contrast to freshly isolated normodense eosinophils which exhibited little capacity to elaborate superoxide in response to FMLP, replicate hypodense eosinophils generated in vitro by coculture with GM-CSF and 3T3 fibroblasts demonstrated a strikingly augmented capacity to generate superoxide when stimulated with FMLP (Fig. 5). The extrapolated ED $_{50}$ for FMLP-stimulated superoxide generation was similar to that observed for FMLP-stimulated $\mathrm{LTC}_{4}$ biosynthesis $\left(\sim 10^{-8}\right.$ and $\sim 2 \times 10^{-8} \mathrm{M}$, respectively). Therefore, the eosinophils are primed to elaborate other proinflammatory mediators, in response to this soluble ligand. The greatly augmented capacity of eosinophils isolated from hypereosinophilic donors to catabolize endogenously generated sulfidopeptide leukotrienes to their subclass-specific diastereoisomeric sulfoxides and to 6trans- $\mathrm{LTB}_{4}$ diastereoisomers $(1,3)$ may relate to the predominant hypodense phenotype of the eosinophils from such patients and their cytokine-driven priming for superoxide generation.

The ability of the 3T3 fibroblasts to significantly augment FMLP-stimulated $\mathrm{LTC}_{4}$ generation by hypodense eosinophils provides further evidence that the fibroblast microenvironment actively participates in the postmitotic determination of eosinophil phenotype. However, it is the GM-CSF component that fulfills the critical role of maintaining cell viability within the microenvironment, which is mandatory for the expression of functional priming by these phenotypically altered cells. Transmembrane activation of the 5-lipoxygenase pathway of human neutrophils and monocytes by particulate activators which are ingested $(33,34)$, human eosinophils by immunoglobulin-coated beads (35), and murine IL-3-dependent bone marrow-derived mast cells by cross-linking of the IgE receptor $(36,37)$ results in the generation of $7-40 \%$ of the leukotriene which is generated by calcium ionophore activation of these cells. Thus, the response of the cytokine-cultured eosinophils appears to provide a model system for the evaluation of soluble ligand-initiated transmembrane stimulation of the 5-lipoxy- 
genase pathway in the absence of phagocytosis (38) or crosslinking of cell surface receptors (35).

\section{Acknowledgments}

This work was supported in part by grants AI-22531, AI-22563, AI23401, HL-36110, and RR-05950 from the National Institutes of Health and in part by a grant from the Hyde and Watson Foundation. Dr. Owen is a recipient of a Robert Wood Johnson Minority Faculty Development Award.

\section{References}

1. Weller, P. F., C. W. Lee, D. W. Foster, E. J. Corey, K. F. Austen, and R. A Lewis. 1983. Generation and metabolism of 5-lipoxygenase pathway leukotrienes by human eosinophils: predominant production of leukotriene $\mathrm{C}_{4}$. Proc. Natl. Acad. Sci. USA. 80:7626-7630.

2. Shaw, R. J., O. Cromwell, and A. B. Kay. 1984. Preferential generation of leukotriene $\mathrm{C}_{4}$ by human eosinophils. Clin. Exp. Immunol. 56:716-722.

3. Owen, W. F., R. J. Soberman, T. Yoshimoto, A. L. Sheffer, R. A. Lewis, and K. F. Austen. 1987. Synthesis and release of leukotriene $C_{4}$ by human eosinophils. J. Immunol. 138:532-538.

4. Lam, B., W. F. Owen, K. F. Austen, and R. J. Soberman. 1989. The identification of a distinct export step following biosynthesis of leukotriene $\mathrm{C}_{4}$ by human eosinophils. J. Biol. Chem. 264:12885-12889.

5. Desimone, C., G. Donell, D. Meli, F. Rosati, and F. Sorice. 1982. Human eosinophils and parasitic diseases. II. Characterization of two cell fractions isolated at different densities. Clin. Exp. Immunol. 48:249-255.

6. Winqvist, I., T. Olofsson, I. Olofsson, A.-M. Perrson, and T. Hallberg. 1982. Altered density, metabolism, and surface receptors of eosinophils in eosinophilia. Immunology. 47:531-539.

7. Prin, L., M. Capron, A.-B. Tonnel, O. Bletry, and A. Capron. 1983. Heterogeneity of human peripheral blood eosinophils: variability in cell density and cytotoxic ability in relation to the level and origin of eosinophilia. Int. Arch. Allergy Appl. Immunol. 72:336-346.

8. Fukuda, T., S. L. Dunette, C. E. Reed, S. J. Ackerman, M. S. Peters, and G. J. Gleich. 1985. Increased numbers of hypodense eosinophils in the blood of patients with bronchial asthma. Am. Rev. Respir. Dis. 132:981-985.

9. Kajita, T., Y. Yui, H. Mita, N. Taniguchi, H. Saito, T. Mishima, and T. Shida. 1985. Release of leukotriene $\mathrm{C}_{4}$ from human eosinophils and its relationship to the cell density. Int. Arch. Allergy Appl. Immunol. 78:406-410.

10. Hodges, M. K., P. F. Weller, N. Gerard, S. J. Ackerman, and J. M. Drazen. 1988. Heterogeneity of leukotriene $C_{4}$ production by eosinophils from asthmatics and from normal subjects. Am. Rev. Respir. Dis. 138:799-804.

11. Rothenberg, M. E., W. F. Owen, D. S. Silberstein, J. Woods, R. J. Soberman, K. F. Austen, and R. L. Stevens. 1988. Human eosinophils have prolonged survival, enhanced functional properties, and become hypodense when exposed to human interleukin 3. J. Clin. Invest. 81:1986-1992.

12. Owen, W. F., M. E. Rothenberg, D. S. Silberstein, J. C. Gasson, R. L. Stevens, K. F. Austen, and R. J. Soberman. 1987. Regulation of human eosinophil viability, density, and function by granulocyte/macrophage colony-stimulating factor in the presence of 3T3 fibroblasts. J. Exp. Med. 166:129-141.

13. Rothenberg, M. E., J. Petersen, D. S. Silberstein, D. McKenzie, K. F. Austen, R. L. Stevens, and W. F. Owen. 1989. Interleukin 5-dependent conversion of normodense eosinophils to the hypodense phenotype uses 3T3 fibroblasts for enhanced viability, accelerated hypodensity, and sustained antibody-dependent cytotoxicity. J. Immunol. 143:2311-2316.

14. Lucey, D. R., D. I. Dorsky, A. Nicholson-Weller, and P. F. Weller. 1989. Human eosinophils express CD4 protein and bind human immunodeficiency virus 1 gp120. J. Exp. Med. 169:327-332.

15. Lucey, D. R., A. Nicholson-Weller, and P. F. Weller. 1989. Mature human eosinophils have the capacity to express HLA-DR. Proc. Natl. Acad. Sci. USA. 86:1348-1351.

16. Tamura, N., D. K. Agrawal, and R. G. Townley. 1988. Leukotriene C production from human eosinophils in vitro: role of eosinophil chemotactic factors on eosinophil activation. J. Immunol. 141:4291-4297.

17. Goetzl, E., and K. F. Austen. 1975. Purification and synthesis of eosinophilotactic tetrapeptides of human lung tissue: identification as eosinophil chemotactic factor of anaphylaxis. Proc. Natl. Acad. Sci. USA. 72:4123-4127.
18. Wardlaw, A. J., R. Moqbel, O. Cromwell, and A. B. Kay. 1986. Plateletactivating factor. A potent chemotactic and chemokinetic factor for human eosinophils. J. Clin. Invest. 78:1701-1706.

19. Corey, E. J., D. A. Clark, and A. Marfat. 1984. The Leukotrienes: Chemistry and Biology. L. W. Chakrin and D. C. Bailey, editors. Academic Press, Inc. Orlando, FL. 14-101.

20. Yoshimoto, T., R. J. Soberman, R. A. Lewis, and K. F. Austen. 1986. Isolation and characterization of leukotriene $C_{4}$ synthetase of rat basophilic leukemic cells. Proc. Natl. Acad. Sci. USA. 82:8399-8403.

21. Ling, C. J., W. F. Owen, and K. F. Austen. 1990. Human fibroblasts maintain the viability and augment the functional response of human neutrophils in culture. J. Clin. Invest. 85:601-604.

22. Seligman, B. T., M. Chusid, and J. L. Gallin. 1984. Differential binding of chemoattractant peptide to subpopulations of human neutrophils. J. Immunol. 133:2641-2646.

23. Clutterbuck, E. J., E. M. Hirst, and C. J. Sanderson. 1989. Human interleukin- 5 regulates the production of eosinophils in human bone marrow cultures: comparison and interaction with IL-1, IL-3, IL-6, and GMCSF. Blood. 73:1504 1512.

24. Le Beau, M. M., R. S. Lemons, R. Espinosa III, R. A. Larson, N. Arai, and J. D. Rowley. 1989. Interleukin-4 and interleukin-5 map to human chromosome 5 in a region encoding growth factors and receptors and are deleted in myeloid leukemias with a del (5q). Blood. 73:647-650.

25. Owen, W. F., M. E. Rothenberg, J. Petersen, P. F. Weller, D. S. Silberstein A. L. Sheffer, R. L. Stevens, R. J. Soberman, and K. F. Austen. 1989. Interleukin5 and phenotypically altered eosinophils in the blood of patients with the idiopathic hypereosinophilic syndrome. J. Exp. Med. 170:343-348.

26. Rothenberg, M. E., W. F. Owen, D. S. Silberstein, R. J. Soberman, K. F Austen, and R. L. Stevens. 1987. Eosinophils cultured with endothelial cells have increased survival and functional properties. Science (Wash. DC). 237:645-647.

27. Pickett, C. B., and A Y. Lu 1989. Glutathione S-transferases: gene structure, regulation, and biological function. Annu. Rev. Biochem. 58:743-764.

28. Gruart, V., J. M. Balloul, L. Prin, M. Tomassini, S. Loiseau, A. Capron, and M. Capron. 1989. Variations in protein expression related to human eosinophil heterogeneity. J. Immunol. 142:4416-4421.

29. Naccache, P. H., N. Faucher, P. Borgeat, J. C. Gasson, and J. DiPersio. 1988. Granulocyte-macrophage colony-stimulating factor modulates the excitation-response coupling sequence in human neutrophils. J. Immunol. 140:35413546.

30. Sullivan, R., J. D. Griffin, E. R. Simons, A. I. Schafer, T. Meshulam, J. P. Fredette, A. K. Maas, A.-S. Gadenne, J. L. Leavitt, and D. A. Melnick. 1987. Effects of recombinant human granulocyte and macrophage colony-stimulating factors on signal transduction pathways in human granulocytes. J. Immunol. 139:3422-3430.

31. DiPersio, J., P. Billing, R. Williams, and J. C. Gasson. 1988. Human granulocyte-macrophage colony-stimulating factor and other cytokines prime human neutrophils for enhanced arachidonic acid release and leukotriene $B_{4}$ synthesis. J. Immunol. 140:4315-4322.

32. Corey, S. J., and P. M. Rosoff. 1989. Granulocyte-macrophage colonystimulating factor primes neutrophils by activating a pertussis toxin-sensitive $G$ protein not associated with phosphatidylinositol turnover. J. Biol. Chem. 264:14615-14671.

33. Williams, J. D., T. H. Lee, R. A. Lewis, and K. F. Austen. 1985. Intracellular retention of the 5-lipoxygenase pathway product, leukotriene $B_{4}$, by human neutrophils activated with unopsonized zymosan. J. Immunol. 134:2624-2630.

34. Williams, J. D., J. K. Czop, and K. F. Austen. 1984. Release of leukotrienes by human monocytes on stimulation of their phagocytic receptor for particulate activators. J. Immunol. 132:3034-3040.

35. Shaw, R. J., G. M. Walsh, O. Cromwell, R. Moqbel, C. J. F. Spry, and A. B. Kay. 1985. Activated human eosinophils generate SRS-A leukotrienes following IgG-dependent stimulation. Nature (Lond.). 316:150-152.

36. Razin, E., J.-M. Mencia-Huerta, R. A. Lewis, E. J. Corey, and K. F. Austen. 1982. Generation of leukotriene $C_{4}$ from a subclass of mast cells differentiated in vitro from mouse bone marrow. Proc. Natl. Acad. Sci. USA. 79:46654667.

37. Razin, E., J.-M. Mencia-Huerta, R. L. Stevens, R. A. Lewis, F.-T. Liu, E. J. Corey, and K. F. Austen. 1983. IgE-mediated release of leukotriene $C_{4}$, chondroitin sulfate $\mathrm{E}$ proteoglycan, $\beta$-hexosaminidase, and histamine from cultured bone marrow-derived mouse mast cells. J. Exp. Med. 157:189-201.

38. Bruynzeel, P. L. B., P. T. M. Kok, M. L. Hamelink, A. M. Kijne, and J. Verhagen. 1985. Exclusive leukotriene $C_{4}$ synthesis by purified human eosinophils induced by opsonized zymosan. FEBS (Fed. Eur. Biochem. Soc.) Lett. 189:350-354. 